\title{
O modeliranju standardnih problema poslovne matematike pomoću rekurzija
}

\author{
Kristina Matijević, Bojan Kovačić
}

\section{Sažetak}

U radu se opisuje matematičko modeliranje nekih standardnih problema poslovne matematike (konačna vrijednost glavnice pri jednostavnom i složenom obračunu kamata, te odredivanje početne, odnosno konačne vrijednosti prenumerando i postnumerando uplata/isplata) pomoću rekurzija. Komentiraju se i neke prednosti takvoga načina modeliranja navedenih problema.

Ključni pojmovi: rekurzije, poslovna matematika, jednostavni kamatni račun, složeni kamatni račun

\section{Uvod}

U nastavi poslovne matematike $u$ srednjim školama, kao i na veleučilištima i samostalnim visokim školama, obrađuju se jednostavni i složeni kamatni račun, te neke njihove standardne primjene (mjenični račun, početna i konačna vrijednost prenumerando i postnumerando uplata i isplata, zajmovi itd.). Pritom se osnovne relacije među promatranim ekonomskim veličinama u tim nastavnim cjelinama najčešće izvode koristeći aritmetičke i geometrijske nizove. U ovom ćemo radu spomenute relacije izvesti koristeći rekurzije. Preciznije, pomoću rekurzija ćemo modelirati tipične problemske zadatke vezane uz jednostavni i složeni kamatni račun. Pritom ćemo detaljno opisati način dobivanja svakoga pojedinoga 
matematičkoga modela kako bismo bolje istaknuli i opisali pripadne ekonomske procese. Standardno matematičko modeliranje svih navedenih problema u srednjoškolskoj i visokoškolskoj nastavi ovdje izostavljamo. Zainteresiranoga čitatelja upućujemo na [1] ili bilo koji udžbenik matematike za 3. razred srednjih ekonomskih škola (vidjeti npr. [4] i [5]).

\section{Pregled potrebnih rezultata iz rekurzija}

U ovoj točki navodimo pregled rezultata koji se odnose na rekurzije, a koje ćemo kasnije efektivno koristiti. Grubo govoreći, rekurzivna relacija ili, skraćeno, rekurzija je relacija pomoću koje se $n$-ti član nekoga niza $\left(a_{n}\right)_{n \in \mathbb{N}_{0}}$ izražava kao funkcija nekoliko svojih prethodnika. Preciznije, kažemo da je niz $\left(a_{n}\right)_{n \in \mathbb{N}_{0}}$ zadan rekurzijom ako postoji veza oblika

$$
a_{n}=f\left(a_{n-1}, \ldots a_{n-k}\right), \forall n \geq k,
$$

pri čemu je $f$ neka funkcija, a početne vrijednosti $a_{0}, \ldots a_{k-1}$ su unaprijed zadane. O rekurzijama i metodama njihova rješavanja detaljnije se može naći npr. u [2] i [3]. U ovom članku promatrat ćemo modele $u$ kojima se koristi linearna rekurzija 1. reda s konstantnim koeficijentima. U tu će nam svrhu biti vrlo korisna sljedeća propozicija.

Propozicija 1. Niz $\left(a_{n}\right)_{n \in \mathbb{N}_{0}}$ zadan je rekurzivno s:

$$
\left\{\begin{array}{l}
a_{n}=\alpha \cdot a_{n-1}+\beta, \quad \forall n \in \mathbb{N}, \\
a_{0}=\gamma,
\end{array}\right.
$$

gdje su $\alpha, \beta, \gamma \in \mathbb{R}, \alpha \neq 0$, (unaprijed zadane) konstante.

a) Ako je $\alpha=1$, onda je:

$$
a_{n}=\beta \cdot n+\gamma
$$

b) Ako je $\alpha \neq 1$, onda je:

$$
a_{n}=\left(\gamma+\frac{\beta}{\alpha-1}\right) \cdot \alpha^{n}-\frac{\beta}{\alpha-1}
$$

Radi ilustracije različitih tehnika rješavanja rekurzija, dat ćemo dva dokaza ove propozicije.

Dokaz I. a) Primijenit ćemo metodu teleskopiranja. Zbrojimo ukupno $n$ jednakosti tako da zasebno zbrojimo njihove lijeve, odnosno 
desne strane:

$$
\begin{aligned}
a_{1} & =a_{0}+\beta, \\
a_{2} & =a_{1}+\beta, \\
& \vdots \\
a_{n-1} & =a_{n-2}+\beta, \\
a_{n} & =a_{n-1}+\beta .
\end{aligned}
$$

Potom poništimo iste članove na različitim stranama dobivene jednakosti, pa dobivamo:

$$
a_{n}=a_{0}+n \cdot \beta
$$

a odatle, zbog početnoga uvjeta $a_{0}=\gamma$, izravno slijedi 2 .

b) Najprije riješimo rekurziju

$$
a_{n}=\alpha \cdot a_{n-1}
$$

Toj rekurziji pridružena karakteristična jednadžba je $x-\alpha=0$. Ona ima jedinstveno rješenje $x=\alpha$. Zbog toga je opće rješenje $a_{n}^{(0)}$ rekurzije (4) dano izrazom:

$$
a_{n}^{(0)}=\lambda \cdot \alpha^{n}
$$

gdje je $\lambda \in \mathbb{R}$ konstanta.

Partikularno rješenje $a_{n}^{\prime}$ rekurzije (1) odredimo metodom neodređenih koeficijenata. „Slobodni član” (preciznije, pribrojnik koji ne sadrži nijedan član niza $\left.\left(a_{n}\right)_{n \in \mathbb{N}_{0}}\right)$ na desnoj strani rekurzije (1) je konstanta $\beta$, pa navedeno partikularno rješenje tražimo u obliku konstante, tj. u obliku

$$
a_{n}^{\prime}=A,
$$

za neki $A \in \mathbb{R}$. Uvrštavanjem $a_{n}^{\prime}=A$ i $a_{n-1}^{\prime}=A \mathrm{u}(1)$ slijedi

$$
A=\alpha \cdot A+\beta,
$$

otkuda je

$$
A=\frac{\beta}{1-\alpha} .
$$

Koristeći (5), (6) i (7) slijedi da je opće rješenje rekurzije (1) dano izrazom:

$$
a_{n}=a_{n}^{(0)}+a_{n}^{\prime}=\lambda \cdot \alpha^{n}+\frac{\beta}{1-\alpha} .
$$


Uvrstimo li $\mathrm{u}(8) n=0$ i iskoristimo početni uvjet $a_{0}=\gamma$, dobit ćemo:

$$
\lambda=\gamma-\frac{\beta}{1-\alpha} .
$$

Uvrštavanjem (9) u i sređivanjem dobivenoga izraza izravno slijedi 3 .

Dokaz II. Nizu $\left(a_{n}\right)_{n \in \mathbb{N}_{0}}$ pridružimo funkciju

$$
f(x)=\sum_{n=0}^{+\infty} a_{n} \cdot x^{n} .
$$

(Funkciju $f$ nazivamo funkcija izvodnica za niz $\left(a_{n}\right)_{n \in \mathbb{N}_{0}}$. ) Tada je:

$$
\alpha \cdot x \cdot f(x)=\sum_{n=0}^{+\infty} \alpha \cdot a_{n} \cdot x^{n+1}=\sum_{n=1}^{+\infty} \alpha \cdot a_{n-1} \cdot x^{n},
$$

pa oduzimanjem 11 od 10 dobivamo:

$$
\begin{aligned}
f(x)-\alpha \cdot x \cdot f(x) & =\sum_{n=0}^{+\infty} a_{n} \cdot x^{n}-\sum_{n=1}^{+\infty} \alpha \cdot a_{n-1} \cdot x^{n} \\
& =a_{0}+\sum_{n=1}^{+\infty} a_{n} \cdot x^{n}-\sum_{n=1}^{+\infty} \alpha \cdot a_{n-1} \cdot x^{n} \\
& =a_{0}+\sum_{n=1}^{+\infty}\left(a_{n}-\alpha \cdot a_{n-1}\right) \cdot x^{n} .
\end{aligned}
$$

No, prema (1) vrijede jednakosti:

$$
\begin{array}{r}
a_{0}=\gamma, \\
a_{n}-\alpha \cdot a_{n-1}=\beta,
\end{array}
$$

pa njihovim uvrštavanjem u 12 dobivamo:

$$
(1-\alpha \cdot x) \cdot f(x)=\gamma+\beta \cdot \sum_{n=1}^{+\infty} x^{n} .
$$

Podsjetimo da za svaki $x \in\langle-1,1\rangle$ vrijede Maclaurinovi razvoji u red potencija:

$$
\begin{aligned}
\frac{1}{1-x} & =\sum_{n=0}^{+\infty} x^{n}, \\
\frac{1}{(1-x)^{2}} & =\sum_{n=1}^{+\infty} n \cdot x^{n-1} .
\end{aligned}
$$


Pomnožimo li s $x$ lijevu i desnu stranu jednakosti (14), dobit ćemo:

$$
\frac{x}{1-x}=\sum_{n=0}^{+\infty} x^{n+1}
$$

odnosno

$$
\frac{x}{1-x}=\sum_{n=1}^{+\infty} x^{n}
$$

Uvrštavanjem 16 u 13 slijedi:

$$
\begin{gathered}
(1-\alpha \cdot x) \cdot f(x)=\gamma+\frac{\beta \cdot x}{1-x}, \\
f(x)=\frac{\gamma}{1-\alpha \cdot x}+\frac{\beta \cdot x}{(1-x) \cdot(1-\alpha \cdot x)} .
\end{gathered}
$$

Da bismo desnu stranu izraza (17) razvili u Maclaurinov red, moramo razlikovati točno dva slučaja: $\alpha=1$ i $\alpha \neq 1$. U potonjem slučaju drugi pribrojnik na desnoj strani izraza (17) možemo dodatno rastaviti na parcijalne razlomke, dok u prvom slučaju to ne možemo učiniti.

Neka je, dakle, najprije $\alpha=1$. Razvijmo desnu stranu jednakosti (17) u Maclaurinov red koristeći (14) i 15. Dobivamo:

$$
\begin{aligned}
f(x) & =\frac{\gamma}{1-x}+\frac{\beta \cdot x}{(1-x)^{2}}=\gamma \cdot \sum_{n=0}^{+\infty} x^{n}+\beta \cdot x \cdot \sum_{n=1}^{+\infty} n \cdot x^{n-1} \\
& =\sum_{n=0}^{+\infty} \gamma \cdot x^{n}+\sum_{n=1}^{+\infty} \beta \cdot n \cdot x^{n}=\sum_{n=0}^{+\infty} \gamma \cdot x^{n}+\sum_{n=0}^{+\infty} \beta \cdot n \cdot x^{n} \\
& =\sum_{n=0}^{+\infty}(\beta \cdot n+\gamma) \cdot x^{n} .
\end{aligned}
$$

Usporedbom koeficijenata uz $x^{n}$ u izrazima (10) i 18 izravno slijedi (2).

Neka je sada $\alpha \neq 1$. Rastavimo drugi pribrojnik u 17 na parcijalne razlomke, pa dobijemo:

$$
\frac{\beta \cdot x}{(1-x) \cdot(1-\alpha \cdot x)}=\frac{\beta}{\alpha-1} \cdot\left(\frac{1}{1-\alpha \cdot x}-\frac{1}{1-x}\right) .
$$

Koristeći 14 i 19, razvijmo desnu stranu jednakosti (17) u Maclauri- 
nov red. Dobivamo:

$$
\begin{aligned}
f(x) & =\left(\gamma+\frac{\beta}{\alpha-1}\right) \cdot \frac{1}{1-\alpha \cdot x}-\frac{\beta}{\alpha-1} \cdot \frac{1}{1-x} \\
& =\left(\gamma+\frac{\beta}{\alpha-1}\right) \cdot \sum_{n=0}^{+\infty}(\alpha \cdot x)^{n}-\frac{\beta}{\alpha-1} \cdot \sum_{n=0}^{+\infty} x^{n} \\
& =\sum_{n=0}^{+\infty}\left(\left(\gamma+\frac{\beta}{\alpha-1}\right) \cdot \alpha^{n}-\frac{\beta}{\alpha-1}\right) \cdot x^{n}
\end{aligned}
$$

pa usporedbom koeficijenata uz $x^{n}$ u izrazima i 20 izravno slijedi (3).

Napomena 1. Iako formula (3) vrijedi $i$ u slučaju $\alpha=0$, u iskazu Propozicije 1 naveli smo uvjet $\alpha \neq 1$. Naime, ako je $\alpha=0$, onda je $s$ (1) definiran niz kojemu su svi članovi osim „nultoga” jednaki $\beta$. Takav niz ovdje nećemo razmatrati.

\section{Osnovne pretpostavke}

U ovoj točki pregledno navodimo pretpostavke i oznake koje ćemo koristiti u modeliranju ekonomskih problema opisanih u sljedećim točkama.

Pretpostavka 1. Ukupno vrijeme kapitalizacije je točno $m \in \mathbb{N}$ godina.

Pretpostavka 2. Zadani (nominalni) kamatnjak je stalan i godišnji.

Pretpostavka 3. Obračun kamata je godišnji.

Koristit ćemo i sljedeće oznake:

$C_{0}$ - iznos na početku razdoblja kapitalizacije;

$K_{n}$ - iznos godišnjih kamata u $n$-toj godini, za svaki $n=1, \ldots, m$;

$p$ - dekurzivni kamatnjak;

$q$ - anticipativni kamatnjak;

$C_{n}$ - iznos kojim raspolažemo na kraju $n$-te godine, za svaki

$$
n=1, \ldots, m \text {; }
$$

$r:=1+\frac{p}{100}-$ dekurzivni kamatni faktor;

$$
\rho=\frac{100}{100-q}-\text { anticipativni kamatni faktor }
$$

Ne istaknemo li drugačije, iznos kojim raspolažemo na kraju svake godine razdoblja kapitalizacije dobiva se tako da se iznosu raspoloživom 
na početku te godine pribroje godišnje kamate. Preciznije, vrijedi jednakost:

$$
C_{n}=C_{n-1}+K_{n} \text {, za svaki } n=1, \ldots, m \text {. }
$$

Napomena 2. Godina kao vremenska jedinica odabrana je isključivo radi određenosti. Moguće je odabrati bilo koju jedinicu vremena, pri čemu se zadani kamatnjak $i$ obračun kamata potom moraju odnositi upravo na odabranu jedinicu.

Napomena 3. U problemima u kojima se javlja dekurzivni kamatnjak pretpostavljamo da je $p>0$. To je tzv. prirodan uvjet na vrijednost toga kamatnjaka. Primijetimo da iz toga uvjeta slijedi $1+\frac{p}{100}>1$, odnosno, $z b o g$ (21), $r>1$.

Napomena 4. U problemima u kojima se javlja anticipativni kamatnjak pretpostavljamo da je $q \in\langle 0,100\rangle$. To je tzv. prirodan uvjet na vrijednost toga kamatnjaka. Primijetimo da iz toga uvjeta slijedi $\frac{100}{100-q}$, odnosno, $z b o g(22), \rho>1$.

Napomena 5. Detaljnija algebarska sređivanja svih algebarskih izraza dobivenih u postupcima rješavanja problema ostavljamo čitateljima kao korisnu vježbu.

\section{Primjene rekurzija na jednostavni kamat- ni račun}

U ovoj točki izvodimo osnovne relacije jednostavnoga kamatnoga računa uz primjenu obaju standardnih načina obračuna kamata (dekurzivnoga, odnosno anticipativnoga).

\subsection{Problem 1}

Iznos od $G$ kn uložimo na $m$ godina uz kamatnjak $p$. Odrediti konačnu vrijednost $S$ uloženoga iznosa na kraju $m$-te godine. Obračun kamata je jednostavan i dekurzivan.

\subsection{Rješenje Problema 1}

Očito je $C_{0}=G$. Pogledajmo kako se dobije iznos $C_{n}$, za svaki $n=$ $1, \ldots, m$. Na početku $n$-te godine raspolažemo s iznosom $C_{n-1}$. Prema pretpostavci, obračun kamata je jednostavan i dekurzivan. Zbog toga je iznos pripadnih godišnjih kamata jednak u svakoj godini razdoblja 
kapitalizacije i računa se u odnosu na glavnicu s početka razdoblja kapitalizacije prema formuli:

$$
K_{n}=\frac{p}{100} \cdot G
$$

Uvrštavanjem ove relacije u 23 slijedi:

$$
C_{n}=C_{n-1}+\frac{p}{100} \cdot G .
$$

Tako smo dobili matematički model:

$$
\left\{\begin{array}{l}
C_{n}=C_{n-1}+\frac{p}{100} \cdot G, \\
C_{0}=G .
\end{array}\right.
$$

Veličine $p$ i $G$ su konstante, pa je model (25) oblika (1), pri čemu su $\alpha=1, \beta=\frac{p}{100} \cdot G$ i $\gamma=G$. Uvrštavanjem tih izraza u $(2)$ dobivamo:

$$
C_{n}=\frac{p \cdot G}{100} \cdot n+G
$$

Traženi iznos $S$ jednak je vrijednosti $C_{m}$, pa uvrštavanjem $n=m$ u 26 konačno dobivamo:

$$
S=\frac{p \cdot G}{100} \cdot m+G=\left(1+\frac{p \cdot m}{100}\right) \cdot G .
$$

\subsection{Problem 2}

Iznos od $G$ kn uložimo na $m$ godina uz anticipativni kamatnjak $q$. Odrediti konačnu vrijednost $S$ uloženoga iznosa na kraju $m$-te godine. Obračun kamata je jednostavan i anticipativan.

\subsection{Rješenje Problema 2}

Očito je $C_{0}=G$. Pogledajmo kako se dobije iznos $C_{n}$, za svaki $n=$ $1, \ldots, m$. Na početku $n$-te godine raspolažemo s iznosom $C_{n-1}$. Prema pretpostavci, obračun kamata je jednostavan i anticipativan. To znači da se kamate u svakoj godini razdoblja kapitalizacije obračunavaju na konačnu vrijednost uloženoga iznosa, tj. vrijednost toga iznosa na kraju razdoblja kapitalizacije. Ta je vrijednost jednaka $S$, pa je iznos godišnjih kamata jednak:

$$
K_{n}=\frac{q}{100} \cdot S
$$

Uvrštavanjem (27) u 23 slijedi:

$$
C_{n}=C_{n-1}+\frac{q}{100} \cdot S
$$


Tako smo dobili matematički model:

$$
\left\{\begin{array}{l}
C_{n}=C_{n-1}+\frac{q}{100} \cdot S, \\
C_{0}=G .
\end{array}\right.
$$

Ovaj model ne možemo riješiti analogno kao i model 25 jer izraz $\frac{q}{100} \cdot S$ nije konstantan (veličina $S$ ovisi o vrijednosti veličine $m$ ). Zbog toga ćemo primijeniti metodu teleskopiranja korištenu u Dokazu I Propozicije 1. Napišimo rekurziju (28) za svaki $n=1, \ldots, m$ :

$$
\begin{aligned}
C_{1} & =C_{0}+\frac{q}{100} \cdot S, \\
C_{2} & =C_{1}+\frac{q}{100} \cdot S, \\
C_{3} & =C_{3}+\frac{q}{100} \cdot S, \\
& \vdots \\
C_{m-1} & =C_{m-2}+\frac{q}{100} \cdot S, \\
C_{m} & =C_{m-1}+\frac{q}{100} \cdot S .
\end{aligned}
$$

Zbrojimo posebno lijeve, a posebno desne strane svih jednakosti u 29. Uočimo da se potom ponište svi članovi osim člana $C_{0}$ na desnoj strani prve jednakosti i člana $C_{m}$ na lijevoj strani posljednje jednakosti. Primijetimo i da se član $\frac{q}{100} \cdot S$ u zbroju pojavljuje ukupno $m$ puta. Tako dobivamo:

$$
C_{m}=C_{0}+m \cdot \frac{q}{100} \cdot S
$$

odnosno, zbog početnoga uvjeta $C_{0}=G$ i očite jednakosti $C_{m}=S$ :

$$
S=G+m \cdot \frac{q}{100} \cdot S
$$

Odatle izrazimo veličinu $S$, pa konačno dobijemo:

$$
S=\frac{100 \cdot G}{100-m \cdot q} \text {. }
$$

\section{Primjene rekurzija na složeni kamatni ra- čun}

U ovoj točki izvodimo osnovne relacije složenoga kamatnoga računa uz primjenu obaju standardnih načina obračuna kamata (dekurzivnoga, odnosno anticipativnoga). 


\section{$5.1 \quad$ Problem 3}

Iznos od $G$ kn uložimo na $m$ godina uz kamatnjak $p$. Odrediti konačnu vrijednost $S$ uloženoga iznosa na kraju $m$-te godine. Obračun kamata je složen i dekurzivan.

\subsection{Rješenje Problema 3}

Očito je $C_{0}=G$. Pogledajmo kako se dobije iznos $C_{n}$ za $n=1, \ldots, m$. $\mathrm{Na}$ početku $n$-te godine raspolažemo s iznosom $C_{n-1}$. Prema pretpostavci, obračun kamata je složen i dekurzivan. Zbog toga iznos godišnjih kamata u $n$-toj godini dobijemo tako da obračunamo (jednostavne) godišnje kamate na iznos $C_{n-1}$. Prema (24), iznos tih kamata jednak je:

$$
K_{n}=\frac{p}{100} \cdot C_{n-1} .
$$

Uvrštavanjem (30) u 23) slijedi:

$$
C_{n}=C_{n-1}+\frac{p}{100} \cdot C_{n-1},
$$

odnosno

$$
C_{n}=\left(1+\frac{p}{100}\right) \cdot C_{n-1} .
$$

Tako smo dobili matematički model:

$$
\left\{\begin{array}{l}
C_{n}=\left(1+\frac{p}{100}\right) \cdot C_{n-1}, \\
C_{0}=G .
\end{array}\right.
$$

Rekurzija (31) je očito rekurzija oblika (1), pri čemu su $\alpha=1+\frac{p}{100}$, $\beta=0$ i $\gamma=G$. Prema Napomeni 3 je $\alpha>1$, pa uvrštavanjem izraza za $\alpha, \beta$ i $\gamma$ u (3) slijedi:

$$
C_{n}=G \cdot\left(1+\frac{p}{100}\right)^{n}
$$

Traženi iznos $S$ jednak je vrijednosti $C_{m}$, pa uvrštavanjem $n=m$ u (33) konačno dobivamo:

$$
S=G \cdot\left(1+\frac{p}{100}\right)^{m} .
$$

Napomena 6. Koristeći (21), formulu (34) možemo kraće zapisati u obliku:

$$
S=G \cdot r^{m} .
$$




\subsection{Problem 4}

Iznos od $G$ kn uložimo na $m$ godina uz kamatnjak $q$. Odrediti konačnu vrijednost $S$ uloženoga iznosa na kraju $m$-te godine. Obračun kamata je složen i anticipativan.

\subsection{Rješenje Problema 4}

Očito je $C_{0}=G$. Pogledajmo kako se dobije iznos $C_{n}$ za svaki $n=$ $1, \ldots, m$. Na početku $n$-te godine raspolažemo s iznosom $C_{n-1}$. Prema pretpostavci, obračun kamata je složen i anticipativan. Zbog toga iznos godišnjih kamata u $n$-toj godini dobijemo obračunavajući te kamate na iznos kojim raspolažemo na kraju $n$-te godine. Taj iznos jednak je $C_{n}$. Dakle, iznos godišnjih kamata u $n$-toj godini jednak je:

$$
K_{n}=\frac{q}{100} \cdot C_{n},
$$

pa uvrštavanjem (36) u 23) slijedi:

$$
C_{n}=C_{n-1}+\frac{q}{100} \cdot C_{n} .
$$

Odatle izrazimo veličinu $C_{n}$, pa dobijemo:

$$
C_{n}=\frac{100}{100-q} \cdot C_{n-1} .
$$

Tako smo dobili matematički model:

$$
\left\{\begin{array}{l}
C_{n}=\frac{100}{100-q} \cdot C_{n-1}, \\
C_{0}=G .
\end{array}\right.
$$

Rekurzija (37) je očito oblika (1), pri čemu su $\alpha=\frac{100}{100-q}, \beta=0$ i $\gamma=G$. Zbog Napomene 4 vrijedi $\alpha>1$, pa model (38) riješimo potpuno analogno kao i model 32 . (Detalje prepuštamo čitatelju.) Dobivamo:

$$
C_{n}=G \cdot\left(\frac{100}{100-q}\right)^{n} .
$$

Traženi iznos $S$ jednak je vrijednosti $C_{m}$, pa iz 39 odmah slijedi:

$$
S=G \cdot\left(\frac{100}{100-q}\right)^{m} .
$$

Napomena 7. Koristeći 222, formulu 400 možemo kraće zapisati u obliku:

$$
S=G \cdot \rho^{m} \text {. }
$$




\section{Primjene rekurzija na izračunavanje ko- načne vrijednosti prenumerando i post- numerando periodičnih nominalno jedna- kih uplata}

U ovoj točki izvodimo osnovne formule vezane uz izračunavanje konačne vrijednosti prenumerando, odnosno postnumerando uplata. Podsjetimo, prenumerando uplate obavljaju se početkom odabranoga vremenskoga razdoblja, a postnumerando uplate krajem toga razdoblja. Radi jednostavnosti, osim ranije navedenih Pretpostavki 1, 2 i 3 primjenjujemo i sljedeće dodatne pretpostavke.

Pretpostavka 4. Sve uplate su nominalno jednake $i$ obavljaju se točno jednom godišnje.

Pretpostavka 5. Osim navedenih godišnjih uplata i pripisa godišnjih kamata, ne razmatramo nikakve druge uplate, isplate $i$ sl.

Pretpostavka 6. Obračun kamata je složen.

\subsection{Problem 5}

Krajem svake od sljedećih m godina na račun uplaćujemo iznos od $R$ kn uz kamatnjak $p$. Odrediti konačnu vrijednost $S$ svih uplata na kraju $m$-te godine. Obračun kamata je dekurzivan.

\subsection{Rješenje Problema 5}

Prema pretpostavci problema, prva uplata će biti izvršena tek na kraju prve godine. Zbog toga na početku razdoblja kapitalizacije nemamo nikakva financijska sredstva. To znači da je $C_{0}=0$.

Pogledajmo kako se dobije iznos $C_{n}$, za svaki $n=1, \ldots, m$. Na početku $n$-te godine raspolažemo s iznosom $C_{n-1}$. Tom iznosu pribrojimo iznos godišnjih kamata u $n$-toj godini i uplaćeni iznos od $R \mathrm{kn}$. Dakle, vrijedi jednakost:

$$
C_{n}=C_{n-1}+K_{n}+R
$$

Odredimo iznos godišnjih kamata. Prema pretpostavci problema, uplata se obavlja krajem godine, pa se godišnje kamate obračunavaju (samo) na iznos $C_{n-1}$. Tako zaključujemo da je

$$
K_{n}=\frac{p}{100} \cdot C_{n-1},
$$


pa uvrštavanjem 42 u 41 slijedi

$$
C_{n}=C_{n-1}+\frac{p}{100} \cdot C_{n-1}+R
$$

odnosno

$$
C_{n}=\left(1+\frac{p}{100}\right) \cdot C_{n-1}+R
$$

Tako smo dobili matematički model:

$$
\left\{\begin{array}{l}
C_{n}=\left(1+\frac{p}{100}\right) \cdot C_{n-1}+R, \\
C_{0}=0
\end{array}\right.
$$

Rekurzija (43) je rekurzija oblika (1), pri čemu su $\alpha=1+\frac{p}{100}, \beta=R$ i $\gamma=0$. Prema Napomeni 3 je $\alpha>1$. Uvrštavanjem izraza za $\alpha, \beta$ i $\gamma \mathrm{u}$ (3), te sređivanjem dobivenoga izraza slijedi:

$$
C_{n}=\left(\left(1+\frac{p}{100}\right)^{n}-1\right) \cdot \frac{100}{p} \cdot R
$$

Traženi iznos $S$ jednak je vrijednosti $C_{m}$, pa uvrštavanjem $n=m$ u 44 konačno dobivamo:

$$
S=\left(\left(1+\frac{p}{100}\right)^{m}-1\right) \cdot \frac{100}{p} \cdot R .
$$

Napomena 8. Formulu 45 možemo zapisati u kraćem obliku koristeći dekurzivni kamatni faktor $r$ definiran formulom (21). Iz (21) najprije slijedi:

$$
\frac{100}{p}=\frac{1}{r-1},
$$

pa se, koristeći 21 $i$ 46, iz 45 dobije:

$$
S=\frac{r^{m}-1}{r-1} \cdot R
$$

\subsection{Problem 6}

Krajem svake od sljedećih $m$ godina na račun uplaćujemo iznos od $R$ kn uz kamatnjak $q$. Odrediti konačnu vrijednost $S$ svih uplata na kraju $m$-te godine. Obračun kamata je anticipativan. 


\subsection{Rješenje Problema 6}

Analogno kao i u rješenju Problema 5, zaključujemo da vrijede jednakost i relacija (41). Odredimo iznos godišnjih kamata. Prema pretpostavci problema, uplate se obavljaju krajem godine, a obračun kamata je anticipativan. Zbog toga se godišnje kamate obračunavaju na iznos na kraju godine umanjen za iznos uplate, tj. na iznos $C_{n}-R$. Tako zaključujemo da vrijedi:

$$
K_{n}=\frac{q}{100} \cdot\left(C_{n}-R\right),
$$

pa uvrštavanjem 48 u 41) slijedi:

$$
C_{n}=C_{n-1}+\frac{q}{100} \cdot\left(C_{n}-R\right)+R,
$$

otkuda je

$$
C_{n}=\frac{100}{100-q} \cdot C_{n-1}+R .
$$

Tako smo dobili matematički model:

$$
\left\{\begin{array}{l}
C_{n}=\frac{100}{100-q} \cdot C_{n-1}+R, \\
C_{0}=0 .
\end{array}\right.
$$

Rekurzija (49) je rekurzija oblika (1), pri čemu su $\alpha=\frac{100}{100-q}, \beta=R$ i $\gamma=0$. Prema Napomeni 3 je $q \in\langle 0,100\rangle$, pa slijedi $\alpha>1$. Uvrštavanjem izraza za $\alpha, \beta$ i $\gamma$ u (3), te sređivanjem dobivenoga izraza slijedi:

$$
C_{n}=\left(\left(\frac{100}{100-q}\right)^{n}-1\right) \cdot\left(\frac{100}{q}-1\right) \cdot R .
$$

Traženi iznos $S$ jednak je vrijednosti $C_{m}$, pa uvrštavanjem $n=m$ u (50) konačno dobivamo:

$$
S=\left(\left(\frac{100}{100-q}\right)^{m}-1\right) \cdot\left(\frac{100}{q}-1\right) \cdot R
$$

Napomena 9. Formulu (51) možemo zapisati u kraćem obliku koristeći anticipativni kamatni faktor $\rho$ definiran formulom 22 . Iz 22] najprije slijedi:

$$
\frac{100}{q}=\frac{\rho}{\rho-1},
$$

pa se, koristeći (22) i (52), iz (51) dobije:

$$
S=\frac{\rho^{m}-1}{\rho-1} \cdot R
$$




\subsection{Problem 7}

Početkom svake od sljedećih $m$ godina na račun uplaćujemo iznos od $R$ kn uz kamatnjak $p$. Odrediti konačnu vrijednost $S$ svih uplata na kraju $m$-te godine. Obračun kamata je dekurzivan.

\subsection{Rješenje Problema 7}

Analogno kao u rješenju Problema 5, zaključujemo da je $C_{0}=0$. Pogledajmo kako se dobije iznos $C_{n}$ za svaki $n=1, \ldots, m$. Na početku $n$-te godine raspolažemo s iznosom $C_{n-1}$. Tom iznosu pribrojimo iznos $R$ uplaćen početkom te godine i iznos godišnjih kamata u $n$-toj godini, pa ponovno vrijedi relacija (41). Međutim, za razliku od Problema 5, u ovome se slučaju kamate obračunavaju i na uplaćeni iznos, odnosno na ukupni iznos $C_{n-1}+R$, pa vrijedi:

$$
K_{n}=\frac{p}{100} \cdot\left(C_{n-1}+R\right) .
$$

Uvrštavanjem (53) u 42 dobivamo:

$$
C_{n}=C_{n-1}+\frac{p}{100} \cdot\left(C_{n-1}+R\right)+R,
$$

otkuda je

$$
C_{n}=\left(1+\frac{p}{100}\right) \cdot C_{n-1}+\left(1+\frac{p}{100}\right) \cdot R .
$$

Tako smo dobili matematički model:

$$
\left\{\begin{array}{l}
C_{n}=\left(1+\frac{p}{100}\right) \cdot C_{n-1}+\left(1+\frac{p}{100}\right) \cdot R, \\
C_{0}=0 .
\end{array}\right.
$$

Rekurzija (54) je rekurzija oblika (1), pri čemu su $\alpha=1+\frac{p}{100}$, $\beta=\left(1+\frac{p}{100}\right) \cdot R$ i $\gamma=0$. Uvrštavanjem tih veličina $\mathrm{u}(3)$ i sređivanjem dobivenoga izraza slijedi:

$$
C_{n}=\left(\left(1+\frac{p}{100}\right)^{n}-1\right) \cdot\left(\frac{100}{p}+1\right) \cdot R
$$

Traženi iznos $S$ jednak je vrijednosti, pa uvrštavanjem $n=m$ u (55) konačno dobivamo:

$$
S=\left(\left(1+\frac{p}{100}\right)^{m}-1\right) \cdot\left(\frac{100}{p}+1\right) \cdot R .
$$

Napomena 10. Koristeći 21] $i$ (46), formulu (56) možemo kraće zapisati u obliku:

$$
S=\frac{r^{m}-1}{r-1} \cdot r \cdot R
$$




\subsection{Problem 8}

Početkom svake od sljedećih $m$ godina na račun uplaćujemo iznos od $R$ kn uz kamatnjak $q$. Odrediti konačnu vrijednost $S$ svih uplata na kraju $m$-te godine. Obračun kamata je anticipativan.

\subsection{Rješenje Problema 8}

Analogno kao u rješenju Problema 7, zaključujemo da vrijede jednakost $C_{0}=0$ i relacija (41). Prema pretpostavci, uplate se obavljaju na početku godine, a obračun kamata je anticipativan. Zbog toga se kamate obračunavaju na iznos $C_{n}$, odnosno vrijedi:

$$
K_{n}=\frac{q}{100} \cdot C_{n} .
$$

Uvrštavanjem (57) u 411) dobivamo:

$$
C_{n}=C_{n-1}+\frac{q}{100} \cdot C_{n}+R
$$

otkuda je

$$
C_{n}=\frac{100}{100-q} \cdot C_{n-1}+\frac{100}{100-q} \cdot R .
$$

Tako smo dobili matematički model:

$$
\left\{\begin{array}{l}
C_{n}=\frac{100}{100-q} \cdot C_{n-1}+\frac{100}{100-q} \cdot R, \\
C_{0}=0 .
\end{array}\right.
$$

Analogno kao u rješenju Problema 5, zaključujemo da za rješavanje rekurzije (58) možemo primijeniti formulu (3). Zbog toga uvrstimo $\alpha=$ $\frac{100}{100-q}, \beta=\frac{100 \cdot R}{100-q}$ i $\gamma=0$ u (3), pa, nakon sređivanja dobivenoga izraza, slijedi:

$$
C_{n}=\left(\left(\frac{100}{100-q}\right)^{n}-1\right) \cdot \frac{100}{q} \cdot R .
$$

Traženi iznos $S$ jednak je vrijednosti $C_{m}$, pa uvrštavanjem $n=m$ u (59) konačno dobivamo:

$$
S=\left(\left(\frac{100}{100-q}\right)^{m}-1\right) \cdot \frac{100}{q} \cdot R .
$$

Napomena 11. Koristeći (22) i (52), formulu (60) možemo kraće zapisati u obliku:

$$
S=\frac{\rho^{m}-1}{\rho-1} \cdot \rho \cdot R .
$$




\section{Primjene rekurzija na izračunavanje po- četne vrijednosti prenumerando i postnu- merando periodičnih nominalno jednakih uplata}

U ovoj točki izvodimo osnovne formule vezane uz izračunavanje početnih vrijednosti prenumerando, odnosno postnumerando isplata. Radi jednostavnosti, osim ranije navedenih retpostavki 1, 2, 3, 6, primjenjujemo i preinačene pretpostavke 4 i 5 .

Pretpostavka 4'. Sve isplate su nominalno jednake i obavljaju se točno jednom godišnje.

Pretpostavka 5'. Osim navedenih godišnjih isplata i pripisa godišnjih kamata, ne razmatramo nikakve druge uplate, isplate $i$ sl.

\subsection{Problem 9}

Odrediti najmanji iznos $S$ koji danas trebamo imati na računu tako da, uz kamatnjak $p$, krajem svake od sljedećih $m$ godina možemo podizati iznos od $R$ kn. Obračun kamata je dekurzivan.

\subsection{Rješenje Problema 9}

Očito je $C_{0}=S$ jer na početku razdoblja kapitalizacije (tj. danas) raspolažemo s iznosom od $S \mathrm{kn}$.

Pogledajmo kako se dobije iznos $C_{n}$ za svaki $n=1, \ldots, m$. Na početku $n$-te godine raspolažemo s iznosom $C_{n-1}$. Tom iznosu pribrojimo godišnje kamate u $n$-toj godini, a oduzmemo isplaćeni iznos $R$. Dakle, vrijedi jednakost:

$$
C_{n}=C_{n-1}+K_{n}-R
$$

Odredimo godišnje kamate. Prema pretpostavci problema, svaka isplata se obavlja krajem godine, pa se kamate obračunavaju na iznos $C_{n-1}$. Zbog toga je:

$$
K_{n}=\frac{p}{100} \cdot C_{n-1},
$$

pa uvrštavanjem 62 u 61 slijedi:

$$
C_{n}=C_{n-1}+\frac{p}{100} \cdot C_{n-1}-R
$$

otkuda je:

$$
C_{n}=\left(1+\frac{p}{100}\right) \cdot C_{n-1}-R
$$


Iz zahtjeva na iznos $S$ slijedi da nakon posljednje $(m$-te) isplate stanje na računu ne smije biti strogo negativno. Zbog toga nužno mora vrijediti nejednakost $C_{m} \geq 0$.

Tako smo dobili matematički model:

$$
\left\{\begin{aligned}
C_{n} & =\left(1+\frac{p}{100}\right) \cdot C_{n-1}-R \\
C_{0} & =S \\
C_{m} & \geq 0
\end{aligned}\right.
$$

Rekurziju 63 riješimo potpuno analogno kao i rekurziju 43). (Detalje prepuštamo čitatelju za vježbu.) Dobivamo:

$$
C_{n}=\left(S-\frac{100 \cdot R}{p}\right) \cdot\left(1+\frac{p}{100}\right)^{n}+\frac{100}{p} \cdot R .
$$

Iz zahtjeva $C_{m} \geq 0$ dobivamo linearnu nejednadžbu:

$$
\left(S-\frac{100 \cdot R}{p}\right) \cdot\left(1+\frac{p}{100}\right)^{m}+\frac{100}{p} \cdot R \geq 0
$$

čije rješenje je

$$
S \geq\left(1-\left(1+\frac{p}{100}\right)^{-m}\right) \cdot \frac{100}{p} \cdot R
$$

Dakle, traženi najmanji iznos je:

$$
S=\left(1-\left(1+\frac{p}{100}\right)^{-m}\right) \cdot \frac{100}{p} \cdot R .
$$

Napomena 12. Koristeći (21) $i$ 46, formulu (64) možemo kraće zapisati u obliku:

$$
S=\frac{r^{m}-1}{r^{m} \cdot(r-1)} \cdot R \text {. }
$$

\subsection{Problem 10}

Odrediti najmanji iznos $S$ koji danas trebamo imati na računu tako da, uz kamatnjak $q$, krajem svake od sljedećih $m$ godina možemo podizati iznos od $R \mathrm{kn}$. Obračun kamata je anticipativan.

\subsection{Rješenje Problema 10}

Analogno kao u rješenju Problema 9, zaključujemo da vrijede jednakost $C_{0}=S$ i relacija (61). Odredimo godišnje kamate. Prema pretpostavci 
problema, svaka isplata se obavlja krajem godine, a obračun kamata je anticipativan. Zbog toga se kamate obračunavaju na iznos prije isplate, tj. na iznos $C_{n}+R$, pa vrijedi:

$$
K_{n}=\frac{q}{100} \cdot\left(C_{n}+R\right) .
$$

Uvrštavanjem 65 u 61 slijedi:

$$
C_{n}=C_{n-1}+\frac{q}{100} \cdot\left(C_{n}+R\right)-R
$$

otkuda je:

$$
C_{n}=\frac{100}{100-q} \cdot C_{n-1}-R .
$$

Iz zahtjeva na iznos $S$ slijedi da nakon posljednje $(m$-te) isplate stanje na računu ne smije biti strogo negativno. Zbog toga nužno mora vrijediti nejednakost $C_{m} \geq 0$.

Tako smo dobili matematički model:

$$
\left\{\begin{aligned}
C_{n} & =\frac{100}{100-q} \cdot C_{n-1}-R, \\
C_{0} & =S \\
C_{m} & \geq 0
\end{aligned}\right.
$$

Rekurziju (66) riješimo potpuno analogno kao i rekurziju 63). (Detalje prepuštamo čitatelju za vježbu.) Dobivamo:

$$
C_{n}=\left(S-\left(\frac{100}{q}-1\right) \cdot R\right) \cdot\left(\frac{100}{100-q}\right)^{n}+\left(\frac{100}{q}-1\right) \cdot R .
$$

Iz zahtjeva $C_{m} \geq 0$ dobivamo linearnu nejednadžbu:

$$
\left(S-\left(\frac{100}{q}-1\right) \cdot R\right) \cdot\left(\frac{100}{100-q}\right)^{m}+\left(\frac{100}{q}-1\right) \cdot R \geq 0
$$

čije rješenje je

$$
S \geq\left(1-\left(\frac{100}{100-q}\right)^{-m}\right) \cdot\left(\frac{100}{q}-1\right) \cdot R
$$

Dakle, traženi najmanji iznos je:

$$
S=\left(1-\left(\frac{100}{100-q}\right)^{-m}\right) \cdot\left(\frac{100}{q}-1\right) \cdot R
$$

Napomena 13. Koristeći (22) $i$ (52), formulu (67) možemo kraće zapisati u obliku:

$$
S=\frac{\rho^{m}-1}{\rho^{m} \cdot(\rho-1)} \cdot R
$$




\subsection{Problem 11}

Odrediti najmanji iznos $S$ koji danas trebamo imati na računu tako da, uz kamatnjak $p$, početkom svake od sljedećih $m$ godina možemo podizati iznos od $R$ kn. Obračun kamata je dekurzivan.

\subsection{Rješenje Problema 11}

Analogno kao u rješenju Problema 9, zaključujemo da vrijede relacija (61), početni uvjet $C_{0}=S$ i nejednakost $C_{m} \geq 0$.

Pogledajmo kako dobijemo iznos godišnjih kamata. Prema pretpostavci problema, svaka isplata se obavlja na početku godine, pa se godišnje kamate u $n$-toj godini obračunavaju na iznos $C_{n-1}-R$. Iznos tih kamata jednak je:

$$
K_{n}=\frac{p}{100} \cdot\left(C_{n-1}-R\right),
$$

pa uvrštavanjem (69) u (61) dobivamo:

$$
C_{n}=C_{n-1}+\frac{p}{100} \cdot\left(C_{n-1}-R\right)-R,
$$

otkuda je

$$
C_{n}=\left(1+\frac{p}{100}\right) \cdot C_{n-1}-\left(1+\frac{p}{100}\right) \cdot R .
$$

Tako smo dobili matematički model:

$$
\left\{\begin{aligned}
C_{n} & =\left(1+\frac{p}{100}\right) \cdot C_{n-1}-\left(1+\frac{p}{100}\right) \cdot R, \\
C_{0} & =S \\
C_{m} & \geq 0 .
\end{aligned}\right.
$$

Rekurziju (70) riješimo potpuno analogno kao i rekurziju (54). (Detalje prepuštamo čitatelju za vježbu.) Dobivamo:

$$
C_{n}=\left(S-\left(\frac{100}{p}+1\right) \cdot R\right)\left(1+\frac{p}{100}\right)^{n}+\left(\frac{100}{p}+1\right) \cdot R .
$$

Iz zahtjeva $C_{m} \geq 0$ dobivamo linearnu nejednadžbu:

$$
\left(S-\left(\frac{100}{p}+1\right) \cdot R\right)\left(1+\frac{p}{100}\right)^{m}+\left(\frac{100}{p}+1\right) \cdot R \geq 0
$$

čije rješenje je:

$$
S \geq\left(1-\left(1+\frac{p}{100}\right)^{-m}\right) \cdot\left(\frac{100}{p}+1\right) \cdot R .
$$

Dakle, traženi najmanji iznos je jednak:

$$
S=\left(1-\left(1+\frac{p}{100}\right)^{-m}\right) \cdot\left(\frac{100}{p}+1\right) \cdot R
$$


Napomena 14. Koristeći 21 $i$ (46), formulu (71) možemo kraće zapisati u obliku:

$$
S=\frac{r^{m}-1}{r^{m-1} \cdot(r-1)} \cdot R \text {. }
$$

\subsection{Problem 12}

Odrediti najmanji iznos $S$ koji danas trebamo imati na računu tako da, uz kamatnjak $q$, početkom svake od sljedećih $m$ godina možemo podizati iznos od $R$ kn. Obračun kamata je anticipativan.

\subsection{Rješenje Problema 12}

Analogno kao u rješenju Problema 11, zaključujemo da vrijede jednakost $C_{0}=S$ i relacija 61 . Odredimo godišnje kamate. Prema pretpostavci problema, svaka isplata se obavlja početkom godine, a obračun kamata je anticipativan. Zbog toga se kamate obračunavaju na iznos $C_{n}$, pa vrijedi:

$$
K_{n}=\frac{q}{100} \cdot C_{n}
$$

Uvrštavanjem 72 u 61 slijedi:

$$
C_{n}=C_{n-1}+\frac{q}{100} \cdot C_{n}-R
$$

otkuda je:

$$
C_{n}=\frac{100}{100-q} \cdot C_{n-1}-\frac{100}{100-q} \cdot R .
$$

Iz zahtjeva na iznos $S$ slijedi da nakon posljednje $(m$-te) isplate stanje na računu ne smije biti strogo negativno. Zbog toga nužno mora vrijediti nejednakost $C_{m} \geq 0$.

Tako smo dobili matematički model:

$$
\left\{\begin{aligned}
C_{n} & =\frac{100}{100-q} \cdot C_{n-1}-\frac{100}{100-q} \cdot R, \\
C_{0} & =S \\
C_{m} & \geq 0
\end{aligned}\right.
$$

Rekurziju (73) riješimo potpuno analogno kao i rekurziju (58). (Detalje prepuštamo čitatelju za vježbu.) Dobivamo:

$$
C_{n}=\left(S-\frac{100}{q} \cdot R\right) \cdot\left(\frac{100}{100-q}\right)^{n}+\frac{100}{q} \cdot R
$$


Iz zahtjeva $C_{m} \geq 0$ dobivamo linearnu nejednadžbu:

$$
\left(S-\frac{100}{q} \cdot R\right) \cdot\left(\frac{100}{100-q}\right)^{n}+\frac{100}{q} \cdot R \geq 0
$$

čije rješenje je

$$
S \geq\left(1-\left(\frac{100}{100-q}\right)^{-m}\right) \cdot \frac{100}{q} \cdot R .
$$

Dakle, traženi najmanji iznos je:

$$
S=\left(1-\left(\frac{100}{100-q}\right)^{-m}\right) \cdot \frac{100}{q} \cdot R .
$$

Napomena 15. Koristeći (22) $i(52)$, formulu 75 možemo kraće zapisati u obliku:

$$
S=\frac{\rho^{m}-1}{\rho^{m-1} \cdot(\rho-1)} \cdot R \text {. }
$$

Napomena 16. U poslovnoj se praksi nešto rjeđe pojavljuju Problemi $6,8,10$ i 12. Ovdje smo ih opisali ne samo radi potpunosti izlaganja, nego $i$ želje da se na metodički odabranim primjerima pokaže kako „funkcionira" anticipativni obračun kamata koji je učenicima $i$ studentima u pravilu manje poznat.

\section{Zaključak}

Prilikom standardnoga matematičkoga modeliranja svih dvanaest promatranih problema poslovne matematike uobičajeno je najprije definirati aritmetički i geometrijski niz, pa potom navesti/izvesti njihova osnovna svojstva (ponajprije, formulu za zbroj prvih $n$ članova niza). Navedena se svojstva primjenjuju u rješavanju spomenutih problema, pri čemu se dodatno koriste još neka načela (npr. načelo financijske ekvivalencije kapitala, načelo matematičke indukcije i dr.). Pritom se načelo matematičke indukcije u razmatranjima najčešće koristi „prešutno”, tj. bez popratnoga detaljnijega opisa. Upravo „prešutna” primjena načela matematičke indukcije zajednička je i standardnom modeliranju i ovdje opisanom modeliranju pomoću rekurzija. Međutim, primijetimo da ni u jednom modelu izloženom u ovom radu ni na koji način nismo spominjali ni aritmetički, ni geometrijski niz. Umjesto njih, naglasak smo stavili na funkcijsko povezivanje vrijednosti glavnice na kraju svake godine s vrijednošću te glavnice na kraju neposredno prethodne godine. Osnovni cilj našega pristupa je razumijevanje procesa kapitalizacije koji se provodi 
u svakoj pojedinoj godini. Na temelju vlastitoga višegodišnjega nastavnoga iskustva tvrdimo da većina studenata prilikom rješavanja ovakvih zadataka očekuje isključivo „gotovu” formulu u koju će uvrstiti zadane podatke i izračunati traženu veličinu. Nerijetko možemo čuti izjavu poput „Ne mogu riješiti taj zadatak jer ne znam formulu”. Time se zapravo učenje gradiva poslovne matematike najčešce svodi na načelo „odredi što je zadano, pronađi odgovarajuću formulu i pomoću nje izračunaj traženo". Smatramo da takva praksa nije dobra, odnosno da bi se bitno više moralo inzistirati na razumijevanju provedenih postupaka. Također, smatramo da obrada potrebnih rezultata iz teorije rekurzija (pregledno navedenih i u ovom članku) nije metodički teža od obrade definicije i osnovnih svojstava aritmetičkoga, odnosno geometrijskoga niza. Zbog toga bi bilo dobro razmotriti opciju da se matematičko modeliranje promatranih problema pomoću rekurzija uvede u nastavne planove i programe poslovne matematike barem na ekonomskim studijima koji se izvode na našim veleučilištima i samostalnim visokim školama. Uvjereni smo da bi takvo modeliranje doprinijelo boljemu razumijevanju promatranih ekonomskih procesa, a što bi rezultiralo i kvalitetnijem ostvarivanju postavljenih ciljeva predmeta.

\section{Literatura}

[1] N. Elezović, Diskontna matematika 1, Element, Zagreb, 2016.

[2] L. Jurišić, A. Marić, Matematika 3, udžbenik i zbirka zadataka za 3. razred srednjih ekonomskih škola, Element, 2014.

[3] B. Relić, Gospodarska matematika, 2. izmijenjeno i dopunjeno izdanje, Hrvatska zajednica računovođa i financijskih djelatnika, Zagreb, 2002.

[4] K. Šrić, Matematika 3, (1. i 2. dio), udžbenik sa zbirkom zadataka, Školska knjiga, Zagreb, 2008.

[5] D. Veljan, Kombinatorna i diskretna matematika, Algoritam, Zagreb, 2001.

Kristina Matijević

Ekonomska škola Požega, Osječka 33, Požega

E-mail adresa: kmatijev@gmail.com 
Bojan Kovačić

Tehničko veleučilište u Zagrebu, Konavoska 2, Zagreb

E-mail adresa: bojan.kovacic@tvz.hr 